\title{
LETTERS
}

\section{Physicians who object to medical assistance in dying}

This letter is in response to a recent CMAJ news article. ${ }^{1}$

It bears emphasizing that freedom of conscience is not the freedom to do what one wants but to do what one must. It is a natural right which is enshrined in the Canadian Charter of Rights and Freedoms, but would exist as a right even if the state did not recognize it. Physicians who object to medical assistance in dying (MAiD) do so because they believe it is not in the best interests of their patients or society in general. We think that the College of Physicians and Surgeons of Ontario would have an interest in upholding such ethical integrity; however, to the contrary, it oversteps its authority and expertise by lecturing objecting physicians that they are wrong about an effective referral constituting assistance in providing MAiD.
Ironically, Dr. Lainie Friedman Ross, a medical ethicist at the University of Chicago, makes the point: “... doctors are powerful individuals and patients are vulnerable." Protecting physicians' right not to harm ultimately safeguards the public.

\section{W. Joseph Askin MD}

Sleep physician, Alberta Committee for Conscience Protection, Calgary, Alta.

\section{Thomas Bouchard MD}

Family physician, Alberta Committee for Conscience Protection, Calgary, Alta.

Cite as: CMAJ 2018 July 16;190:E861. doi: $10.1503 / \mathrm{cmaj} .69464$

\section{Reference}

1. Glauser W. Canada and US going in opposite directions on conscientious objection for doctors. CMAJ 2018;190:E270-1.

Competing interests: W. Joseph Askin and Thomas Bouchard are co-chairs of the Alberta Committee for Conscience Protection. 